Bangladesh J. Sci. Ind. Res. 42(3), 287-298, 2007

\title{
Extraction of Gasohol Grade Ethanol from Aqueous Solution using Gasoline as Solvent
}

\author{
M. A. Rahman, M. Asadullah,* M. S. Rahman, M. N. Nabi and M. A. K. Azad \\ Department of Applied Chemistry and Chemical Technology \\ University of Rajshahi, Rajshahi 6205, Bangladesh
}

\begin{abstract}
Liquid-liquid phase equilibria of ethanol - water - gasoline ('iso-octane', 'octane' 'petrol', 'kerosene' and 'diesel') were experimentally determined and the ternary phase diagrams of the systems were studied with an end in view to develop methods of producing 'gasohol' by a once through operation. Binodal curves of the different systems were, therefore, obtained to give quantitative ideas about the extent of extraction of alcohol from aqueous solution using gasoline. Phase equilibrium data, distribution coefficient and separation factor were obtained experimentally for ethanolwater-gasoline systems. The order of the heterogeneous region of the solvents is isooctane . 'octane' .'petrol' < 'kerosene' < 'diesel'. The equilibriation and settling time for ethanol - water - solvent systems are about 10 and $20 \mathrm{~min}$, respectively. The solubility of ethanol in the solvents is in the order of iso-octane 'octane' ' 'petrol' > 'kerosene' > 'diesel'. The distribution coefficient increases with increasing ethanol concentration in the feed; however, to the contrary the separation factor decreases. The distribution co-efficients are lower than 1 and the separation factors are greater than 10 for all of the solvents.
\end{abstract}

Key words : Gasohol, solvent, solvent extraction, gasoline and liquid-liquid equilibria.

\section{Introduction}

According to the projections from the World Energy Council and others world's estimated recoverable oil reserves of 1 trillion barrels and natural gas reserves of 5000 trillion cubic feet (Tcf) should both be available through out the 21st century and proved recoverable reserves of coal of 984 billion tons at the present rate of production could be available for more than 200 years. This limitation of fossil fuel sources is threatening to the energy depended future generation. Therefore, alternative sources of energy are seriously sought (Tomishig and Asadullah, 2005). Possibilities of production of hydrocarbons as substitute of natural gas and gasoline has been studied by hydrogenation of carbon dioxide, $\mathrm{CO}_{2}$ (Reverse Water Gas Synthesis, RWGS) (Choi et al. 1996) and reforming of

*Correspondence should be made : asad@ru.ac.bd; asadullah8666@yahoo.com 
carbon monoxide, CO (Fischer-Tropsch Synthesis, FT) have been studied (Zhang et al. 2002 and Wang et al. 2003). A valuable renewable source of energy could be the biomass (agricultural wastes, forestry wastes and city wastes) whose pyrolysis and gasification may yield liquid and gaseous products which may be used as diesel and natural gas alternative (Bridgwater 1996). Unfortu-nately, high technology is involved in the aforesaid process due to unavoidable use of heterogeneous catalysts and enormous volumes of research are yet to be done before these processes could be exploited commercially.

Petroleum dependence for gasoline may be reduced to some extent by using mixture of ethanol and gasoline. A mixture of $10 \mathrm{vol} \%$ ethanol and 90 vol \% gasoline popularly known as 'Gasohol' is in use commercially as a good substitute of gasoline (Pimentel 2003). But the conventional method of distillation and azeotropic distillation for the recovery of ethanol to an almost water free state as required for 'gasohol' from a renewable source like fermentation broth is an energy intensive operation; energy requirement is about 27,000 Btu/USgallon of ethanol (Tomishig and Asadullah 2005). Liquid-liquid extraction of ethanol from its dilute solutions could be a cheap means for separation and purification of ethanol and a number of solvents have been tried for this purpose (Rahman et al. 1995) but again the problem of separation of solvent from ethanol is encountered here. Solvent separa- tion may be avoided by using gasoline as solvents. In the present work possibility of extraction of ethanol from its dilute aqueous solution using gasoline as solvent has been studied.

\section{Experimental}

Materials: Gasolines commercially known as 'octane', 'petrol', 'diesel' and 'kerosene' were obtained from the local gas station and characterized by determining their boiling ranges, densities and refractive indices as follows.

\begin{tabular}{lccc} 
Gasoline & $\begin{array}{c}\text { Boiling } \\
\text { range, }{ }^{\mathrm{O}} \mathrm{C}\end{array}$ & $\begin{array}{c}\text { Density, } \\
\mathrm{g} / \mathrm{cm}^{3}\end{array}$ & $\begin{array}{c}\text { Refractive } \\
\text { index, } \mathrm{\eta D}^{20}\end{array}$ \\
Iso-octane & 99.5 & 0.693 & 1.3843 \\
'Octane' & $150-180$ & 0.701 & 1.4250 \\
'Petrol' & $168-200$ & 0.729 & 1.4110 \\
'Diesel' & $250-320$ & 0.820 & 1.4536 \\
'Kerosene' & $200-260$ & 0.795 & 1.4387 \\
Dilute ethanol solutions were prepared from \\
\multicolumn{4}{l}{ rectified spirit and water. }
\end{tabular}

Equipment : Electric shaker (Model: 1866; Jencons Scientific Ltd., England), Thermostatic water bath (Model: SB-3; Grants Instruments Ltd., England) and Gas Chromatograph (Model: Shimadzu GC-14B) were used in this work.

Procedures : All the extractions were carried out by shaking two phases (aqueous and organic) contained in closed Erlenmeyer flasks. The flask was tightly closed and fixed 
to a shaft of a electrically driven flask shaker. Then the flask was placed in a thermostatic bath. The temperature range of the thermostatic bath was $0^{\circ} \mathrm{C}$ to $100^{\circ} \mathrm{C}$ with a controller accuracy of $\pm 0.1^{\circ} \mathrm{C}$. The shaker had a maximum capacity of eight flasks to be shaken at a time. The shaking speed was controlled by a regulator.

For extraction process, precise liquid-liquid equilibrium data is required. The cloud-point method was used for producing the data for the binodal curve of the ternary system. For this experiment $10 \mathrm{~cm}^{3}$ of water was taken into a $125 \mathrm{~cm}^{3}$ closed Erlenmeyer flask and solvent (gasoline) was added from a burette and agitated till the solution started to appear turbid. The solution was kept undisturbed for about $2 \mathrm{~h}$ at a constant temperature $\left(25 \pm 0.1^{\mathrm{O}} \mathrm{C}\right)$. The amount of solvent added was recorded as the maximum solubility of the solvent in the water and gave the first point of the binodal curve on the base line. The appearance of the turbidity indicated the beginning of the formation of the second phase, the solvent layer. Therefore, the further addition of a small amount of solvent gave a heterogeneous mixture. Then ethanol was added from a burette until the first appearance of distinct clear homogeneity. This gave another point of binodal curve on the triangular diagram. This procedure was repeated to construct the binodal curve on the aqueous side. Same procedure was applied starting with an initially measured quantity of solvent to construct the binodal curve on the solvent side.

The samples from each phase were taken at the end of each experiment and analyzed by means of a Shimadzu GC-14B gas chromatograph equipped with a flame ionization detector. A $30 \mathrm{~m} \times 0.25 \mathrm{~mm}$ i.d. Alltech capillary column (coated with $\mathrm{AT}^{\mathrm{TM}}-5$, $30 \mathrm{~m} \times 0.2 \mathrm{~mm}$ i.d.) was used isothermally for component separation. The column and detector temperatures were maintained at 120 and $250^{\circ} \mathrm{C}$, respectively. For the quantitative measurement, n-heptane was used as an internal standard. The amount of each component was measured in weight, which is then converted to weight fraction.

For the separation of ethanol from water, the feed to ethanol ratio and equilibrium contact time were optimized. For the optimum feed to ethanol ratio, the experiments were performed using the solution of $20 \mathrm{~cm}^{3}$ water and $10 \mathrm{~cm}^{3}$ ethanol in four different $250 \mathrm{~cm}^{3}$ closed Erlenmeyer flasks. The different amounts of solvents were added into the flasks and the flasks were shaken for about 4 $\mathrm{h}$ and allowed to settle for about $2 \mathrm{~h}$ at $25 \pm 0.1^{\mathrm{O}} \mathrm{C}$. For the determination of optimum contact time, the flasks were shaken for different times from 1 to $30 \mathrm{~h}$. The samples of aqueous and organic phases were analyzed by gas chromatograph, Shimadzu GC-14B. 


\section{Results and Discussion}

\section{Determination of the composition of organic} and aqueous phases

The equilibrium extraction of ethanol from dilute aqueous solution using commercial gasoline- 'octane' 'petrol' 'kerosene' and 'diesel' was carried out and compared with that of analytical grade iso-octane at $25 \pm 0.1^{\mathrm{O}}$ C. The compositions of the organic and aqueous phases experimentally determined are given in Table I. The concentrations of ethanol and solvents were determined by gas chromatography and the concentration of water was determined by using a triangular coordinate plot with one side as a base; the left vertex represents $100 \%$ water, the right vertex represents $100 \%$ solvent, and the top vertex represents $100 \%$ solute. Other percent lines for the respective components are laid off at proportional distances along the altitude joining each vertex with the opposite side; the length of this altitude is taken as $100 \%$. The sum of the vertical distances to the three sides from any point within the triangle is also equal to $100 \%$, from geometric considerations; thus the plotting of the values for the percentages of any two compounds of a ternary system determines a point in the triangle, fixes the percentage of the third component, and checks the corresponding arithmetic.

The binodal curves of ethanol-water-solvent systems are plotted in Figures 1a, 1b, 1c, 1d and 1e. From this figure it is seen that the binary systems of water-solvents are immiscible and the binary systems of ethanolsolvents are miscible at temperature, (25 \pm $0.1^{\mathrm{O}} \mathrm{C}$ ). It is also seen that the miscibility of water in solvent is larger than that of solvent in water. The miscibility of solvent in water is very low. The miscibility of solvent - water binary systems decreases with increasing number of carbon atoms in the chain of Hydrocarbon solvents. It is also observed that the ascending order of heterogeneous region of the binodal curves for the solvents can be presented as 'octane' . iso-octane > 'kerosene' > 'diesel'.

\section{Effect of contact time on ethanol extraction}

The effect of contact time on ethanol extraction has been studied at temperature, $\left(25 \pm 0.1^{\mathrm{O}} \mathrm{C}\right)$. These results are summarized in Table II. Distribution coefficient of ethanol (KD) has been plotted against phase contact time for ethanol-water-solvent systems in Figure 2. It is seen from this figure that the value of the distribution coefficient of ethanol increases with increasing the phase contact time and attains a maximum value at $10 \mathrm{~min}$. So the equilibrium time can be taken as $10 \mathrm{~min}$, but $30 \mathrm{~min}$ have been allowed to ensure equilibration. It is further seen that dispersed phases separated into two distinct phases within $20 \mathrm{~min}$, after shaking, but 30 min have been allowed to ensure setting. 
Table I. Compositions of equilibrium phases of ethanol - water - hydrocarbon systems at $30 \pm 0.1^{\circ} \mathrm{C}$

\begin{tabular}{|c|c|c|c|c|c|c|}
\hline \multirow[t]{2}{*}{ Solvent } & \multicolumn{3}{|c|}{ Composition of water rich phase, (wt \%) } & \multicolumn{3}{|c|}{ Composition of solvent rich phase, (wt\%) } \\
\hline & Water & Solvent & Ethanol & Water & Solvent & Ethanol \\
\hline \multirow[t]{10}{*}{ 'Octane' } & 100.0 & 0 & 0 & 0.0 & 100.0 & 0.0 \\
\hline & 74.0 & 0.3 & 25.7 & 0.4 & 81.8 & 17.8 \\
\hline & 57.6 & 0.5 & 41.9 & 1.0 & 73.0 & 26.0 \\
\hline & 46.8 & 0.7 & 52.5 & 1.6 & 62.5 & 35.9 \\
\hline & 35.8 & 1.7 & 62.5 & 3.3 & 43.4 & 53.3 \\
\hline & 29.8 & 2.4 & 67.8 & 4.3 & 34.4 & 61.3 \\
\hline & 20.4 & 5.2 & 74.4 & 6.1 & 24.4 & 69.5 \\
\hline & 16.2 & 7.5 & 76.3 & 7.3 & 19.3 & 73.4 \\
\hline & 13.8 & 8.8 & 77.3 & 8.3 & 16.7 & 75.0 \\
\hline & 12.4 & 9.9 & 77.7 & 10.0 & 13.4 & 76.6 \\
\hline \multirow[t]{7}{*}{ Iso-octane } & 100.0 & 0.0 & 0.0 & 0 & 100.0 & 0 \\
\hline & 47.2 & 0.6 & 52.2 & 2.4 & 41.4 & 56.2 \\
\hline & 34.8 & 1.4 & 63.8 & 4.5 & 30.7 & 64.8 \\
\hline & 29.0 & 2.4 & 68.6 & 6.7 & 23.1 & 70.2 \\
\hline & 24.4 & 3.3 & 72.3 & 9.8 & 16.8 & 73.4 \\
\hline & 18.0 & 7.4 & 74.6 & 11.8 & 13.4 & 74.8 \\
\hline & 14.8 & 10.1 & 75.1 & - & - & - \\
\hline \multirow[t]{10}{*}{ 'Petrol’ } & 100 & 0 & 0 & 0 & 100.0 & 0 \\
\hline & 73.2 & 0.2 & 26.6 & 0.6 & 81.7 & 17.7 \\
\hline & 57.6 & 0.5 & 41.9 & 1.0 & 71.3 & 27.7 \\
\hline & 53.5 & 0.8 & 45.7 & 1.5 & 56.8 & 41.7 \\
\hline & 42.2 & 1.8 & 56.0 & 3.6 & 43.6 & 52.8 \\
\hline & 28.6 & 2.1 & 69.3 & 4.7 & 34.7 & 60.6 \\
\hline & 24.6 & 3.6 & 71.8 & 6.8 & 25.1 & 68.1 \\
\hline & 20.0 & 5.8 & 74.2 & 9.7 & 17.7 & 72.6 \\
\hline & 17.3 & 8.0 & 74.7 & 11.5 & 14.2 & 74.3 \\
\hline & 15.8 & 9.2 & 75.0 & 13.1 & 12.0 & 74.9 \\
\hline \multirow[t]{7}{*}{ 'Kerosene' } & 100.0 & 0 & 0 & 0 & 100.0 & 0 \\
\hline & 36.3 & 0.1 & 63.6 & 0.2 & 47.4 & 52.4 \\
\hline & 29.1 & 0.2 & 70.7 & 0.6 & 42.7 & 56.7 \\
\hline & 25.3 & 0.4 & 74.3 & 0.9 & 35.5 & 63.6 \\
\hline & 18.2 & 1.4 & 80.4 & 2.7 & 21.3 & 76.0 \\
\hline & 15.1 & 2.3 & 82.6 & 3.9 & 15.6 & 80.5 \\
\hline & 10.9 & 5.1 & 84.0 & 7.2 & 9.3 & 83.5 \\
\hline \multirow[t]{7}{*}{ 'Diesel’ } & 100.0 & 0.0 & 0.0 & 0 & 100 & 0 \\
\hline & 26.1 & 0.1 & 73.8 & 0.2 & 31.8 & 68.0 \\
\hline & 22.6 & 0.2 & 77.2 & 0.4 & 28.9 & 70.7 \\
\hline & 20.4 & 0.3 & 79.3 & 0.6 & 25.2 & 74.2 \\
\hline & 14.5 & 1.2 & 84.3 & 1.9 & 15.9 & 82.2 \\
\hline & 11.7 & 1.9 & 86.4 & 2.9 & 11.9 & 85.2 \\
\hline & 8.4 & 4.1 & 87.5 & 5.5 & 7.5 & 87.0 \\
\hline
\end{tabular}



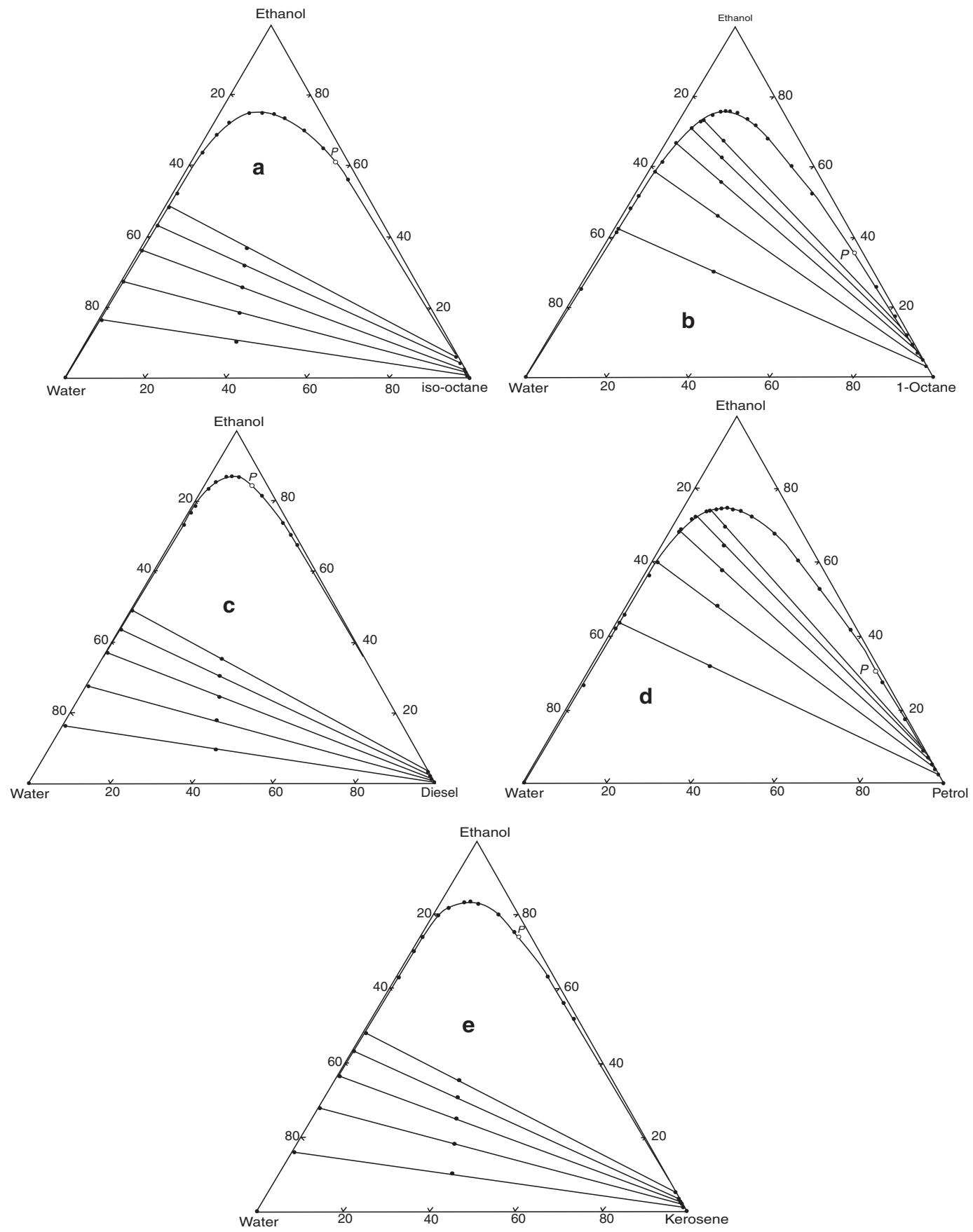

Fig. 1. Binodal curve and tie lines for ethanol-water-solvent systems at $25 \pm 0.1^{\mathrm{O}} \mathrm{C}$. a: ethanol-water-iso-octane; b: ethanol-water-1-octane; c: ethanol-water-diesel; d: ethanol-water-petrol and e: ethanol-water-kerosene. 
Table II. Effect of contact time on the composition of organic and aqueous phases

\begin{tabular}{|c|c|c|c|c|c|c|c|c|}
\hline \multirow[t]{2}{*}{ Solvent } & \multirow{2}{*}{\begin{tabular}{|c|} 
Phase \\
contact \\
time,(min) \\
\end{tabular}} & \multicolumn{3}{|c|}{$\begin{array}{c}\text { Composition of } \\
\text { organic phase, (wt \%) }\end{array}$} & \multicolumn{3}{|c|}{$\begin{array}{c}\text { Composition of organic } \\
\text { phase, (wt \%) }\end{array}$} & \multirow{2}{*}{$\begin{array}{c}\begin{array}{c}\text { Distribution } \\
\text { coefficient } \\
\text { of ethanol }\end{array} \\
\mathrm{K}_{\mathrm{D}} \\
\end{array}$} \\
\hline & & $X_{W}$ & $X_{S}$ & $X_{E}$ & $X_{W}$ & $\mathrm{X}_{\mathrm{S}}$ & $X_{E}$ & \\
\hline \multirow[t]{8}{*}{ Octane } & 0.50 & 0.08 & 97.12 & 2.80 & 51.30 & 0.80 & 47.90 & 0.058 \\
\hline & 2.00 & 0.09 & 97.01 & 2.90 & 54.50 & 0.70 & 44.80 & 0.065 \\
\hline & 5.00 & 0.10 & 96.90 & 3.00 & 55.90 & 0.60 & 43.50 & 0.069 \\
\hline & 10.00 & 0.10 & 96.80 & 3.10 & 56.70 & 0.60 & 42.70 & 0.073 \\
\hline & 15.00 & 0.10 & 96.80 & 3.10 & 56.70 & 0.60 & 42.70 & 0.073 \\
\hline & 20.00 & 0.10 & 96.80 & 3.10 & 56.70 & 0.60 & 42.70 & 0.073 \\
\hline & 25.00 & 0.10 & 96.80 & 3.10 & 56.70 & 0.60 & 42.70 & 0.073 \\
\hline & 30.00 & 0.10 & 96.80 & 3.10 & 56.70 & 0.60 & 42.70 & 0.073 \\
\hline \multirow{8}{*}{$\begin{array}{l}\text { Iso- } \\
\text { octane }\end{array}$} & 0.50 & 0.08 & 99.02 & 0.90 & 77.80 & 0.30 & 21.90 & 0.041 \\
\hline & 2.00 & 0.09 & 98.91 & 1.00 & 80.30 & 0.20 & 19.50 & 0.051 \\
\hline & 5.00 & 0.10 & 98.80 & 1.10 & 82.80 & 0.10 & 17.10 & 0.064 \\
\hline & 10.00 & 0.10 & 98.70 & 1.20 & 83.40 & 0.10 & 16.50 & 0.073 \\
\hline & 15.00 & 0.10 & 98.70 & 1.20 & 83.40 & 0.10 & 16.50 & 0.073 \\
\hline & 20.00 & 0.10 & 98.70 & 1.20 & 83.40 & 0.10 & 16.50 & 0.073 \\
\hline & 25.00 & 0.10 & 98.70 & 1.20 & 83.40 & 0.10 & 16.50 & 0.073 \\
\hline & 30.00 & 0.10 & 98.70 & 1.20 & 83.40 & 0.10 & 16.50 & 0.073 \\
\hline \multirow[t]{8}{*}{ 'Petrol' } & 0.500 & 0.09 & 98.21 & 1.70 & 49.20 & 0.90 & 49.90 & 0.034 \\
\hline & 2.00 & 0.10 & 97.70 & 2.20 & 80.3 & 0.80 & 47.60 & 0.046 \\
\hline & 5.00 & 0.11 & 97.50 & 2.30 & 82.80 & 0.70 & 45.00 & 0.051 \\
\hline & 10.00 & 0.11 & 97.50 & 2.39 & 83.40 & 0.70 & 43.30 & 0.055 \\
\hline & 15.00 & 0.11 & 97.50 & 2.39 & 83.40 & 0.70 & 43.30 & 0.055 \\
\hline & 20.00 & 0.11 & 97.50 & 2.39 & 83.40 & 0.70 & 43.30 & 0.055 \\
\hline & 25.00 & 0.11 & 97.50 & 2.39 & 83.40 & 0.70 & 43.30 & 0.055 \\
\hline & 30.00 & 0.11 & 97.50 & 2.39 & 83.40 & 0.70 & 43.30 & 0.055 \\
\hline 'Keros & 0.50 & 0.03 & 99.47 & 0.50 & 80.14 & 0.06 & 19.80 & 0.025 \\
\hline \multirow[t]{7}{*}{ ene’ } & 2.00 & 0.04 & 99.31 & 0.60 & 81.95 & 0.05 & 18.00 & 0.033 \\
\hline & 5.00 & 0.04 & 99.28 & 0.65 & 83.06 & 0.04 & 16.90 & 0.038 \\
\hline & 10.00 & 0.04 & 99.28 & 0.68 & 83.85 & 0.04 & 16.11 & 0.042 \\
\hline & 15.00 & 0.04 & 99.28 & 0.68 & 83.85 & 0.04 & 16.11 & 0.042 \\
\hline & 20.00 & 0.04 & 99.28 & 0.68 & 83.85 & 0.04 & 16.11 & 0.042 \\
\hline & 25.00 & 0.04 & 99.28 & 0.68 & 83.85 & 0.04 & 16.11 & 0.042 \\
\hline & 30.00 & 0.04 & 99.28 & 0.68 & 83.85 & 0.04 & 16.11 & 0.042 \\
\hline \multirow[t]{8}{*}{ Diesel } & 0.500 & 0.01 & 99.74 & 0.25 & 81.05 & 0.05 & 18.90 & 0.013 \\
\hline & 2.00 & 0.02 & 99.72 & 0.26 & 82.26 & 0.04 & 17.70 & 0.015 \\
\hline & 5.00 & 0.02 & 99.71 & 0.27 & 82.97 & 0.03 & 17.00 & 0.016 \\
\hline & 10.00 & 0.02 & 99.70 & 0.28 & 83.70 & 0.03 & 16.27 & 0.017 \\
\hline & 15.00 & 0.02 & 99.70 & 0.28 & 83.70 & 0.03 & 16.27 & 0.017 \\
\hline & 20.00 & 0.02 & 99.70 & 0.28 & 83.70 & 0.03 & 16.27 & 0.017 \\
\hline & 25.00 & 0.02 & 99.70 & 0.28 & 83.70 & 0.03 & 16.27 & 0.017 \\
\hline & 30.00 & 0.02 & 99.70 & 0.28 & 83.70 & 0.03 & 16.27 & 0.017 \\
\hline
\end{tabular}




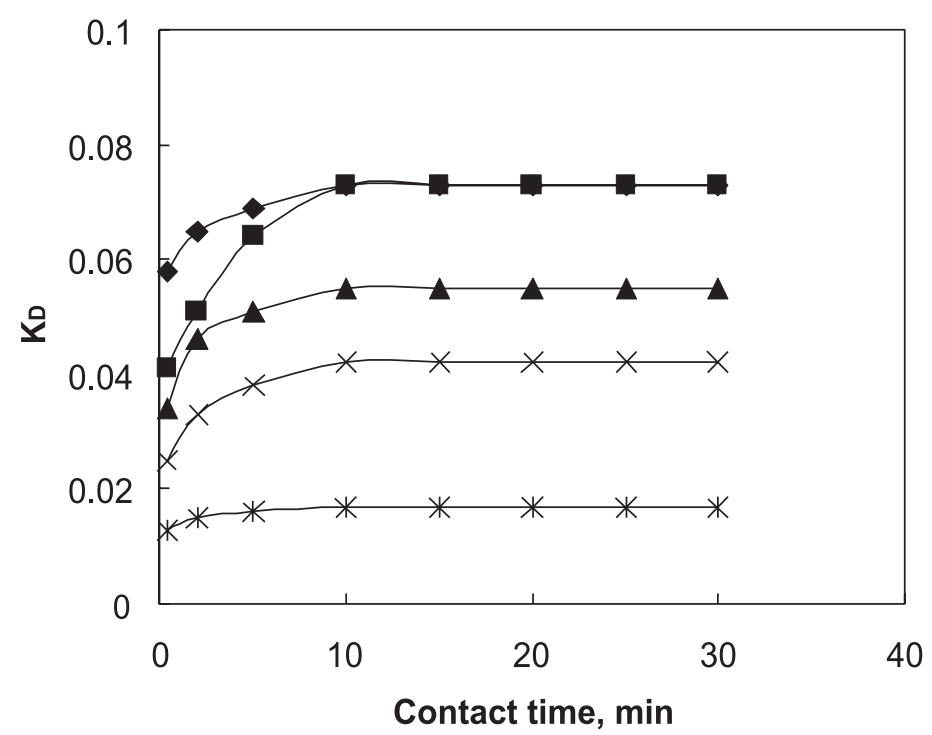

Fig. 2. Effect of contact time on distribution coefficient of ethanol-water-solvent systems. $(\diamond) 1$ - octane, ( ) iso-octane, $(\Delta)$ petrol, $(\times)$ kerosene and $(*)$ diesel.

Compositions of coexisting phases in the ethanol-water-solvent systems

The equilibrium tie line data of the, ethanolwater-iso-octane, ethanol-water-'octane', ethanol-water- 'petrol', ethanol-water-'kerosene', and ethanol-water-'diesel' systems are determined at $\left(25 \pm 0.1^{\mathrm{O}} \mathrm{C}\right)$. The compositions of the coexisting phases are presented in Table III. The distribution coefficient and separation factor between the coexisting liquid phases have been calculated, separation factor is determined numerically from the tie line data because it is the ratio of distribution coefficient of ethanol to the distribution coefficient of water. The distribution coefficient of ethanol $\mathrm{K}_{\mathrm{D}}$ is the ratio of concentration of ethanol in organic and aqueous phases, respectively. Similarly the distribution coefficient of water $\mathrm{K}_{\mathrm{W}}$ is the ratio of concentration of water in organic and aqueous phases, respectively. These results are given in Table III. These data allowed us to draw the corresponding equilibrium distribution curves in Figure 3 and equilibrium separation factor in Figure 4. Figure 3 shows that the concentration of ethanol in organic phase increases with increasing concentration of ethanol in aqueous phase.

Since the concentration of ethanol in isooctane, 'octane', 'petrol' 'diesel', and 'kerosene' is lower than that in water - rich phase; water has stronger affinity for ethanol than iso-octane, 'octane', 'petrol', 'diesel', and 'kerosene'. From Figure 1 it is seen that 


\begin{tabular}{|c|c|}
\hline 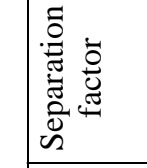 & 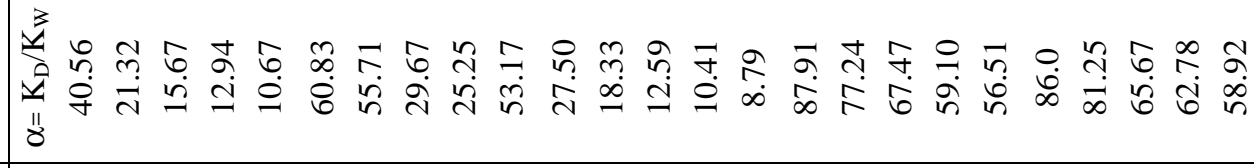 \\
\hline 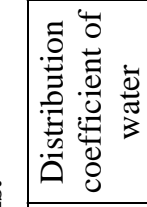 & 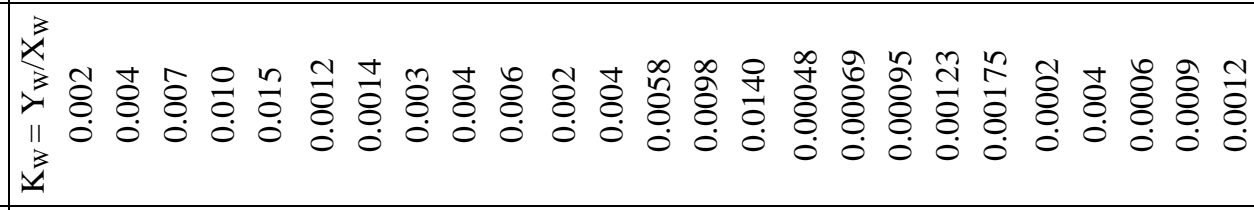 \\
\hline 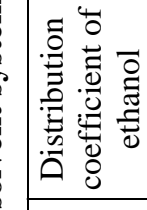 & 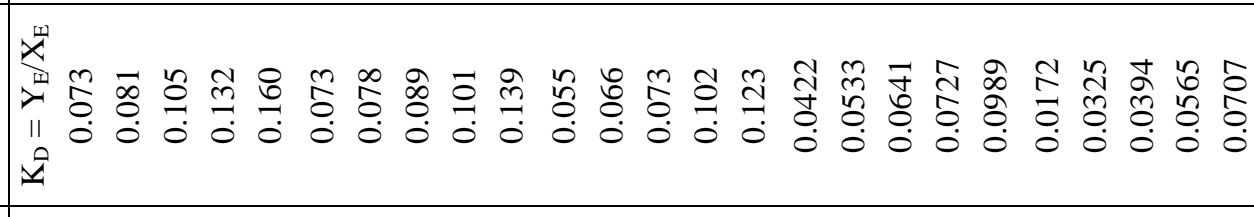 \\
\hline 号 & 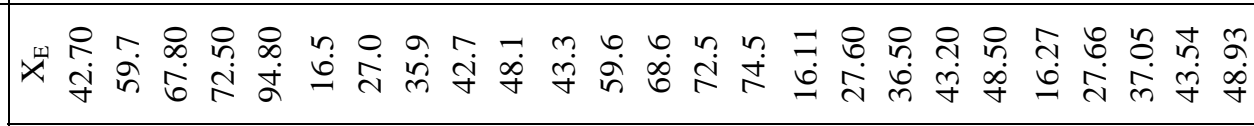 \\
\hline 要 & $\varkappa$ « \\
\hline$\overbrace{\bar{\Xi}}$ & 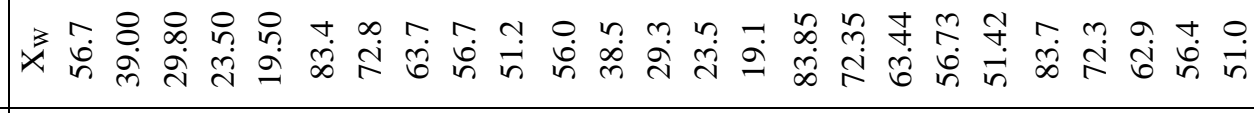 \\
\hline $4 \stackrel{\circ}{\frac{\partial}{3}}$ & 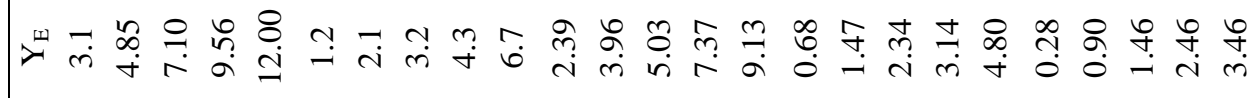 \\
\hline 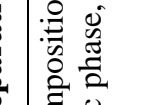 & 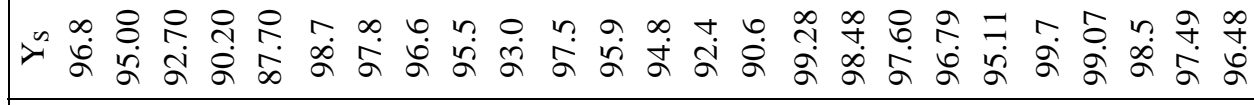 \\
\hline 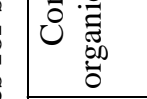 & 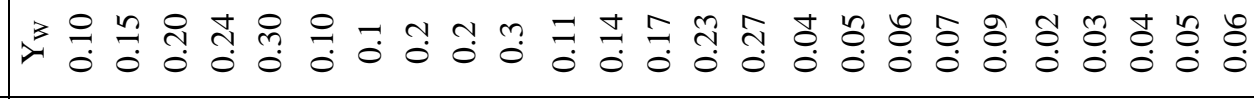 \\
\hline : & 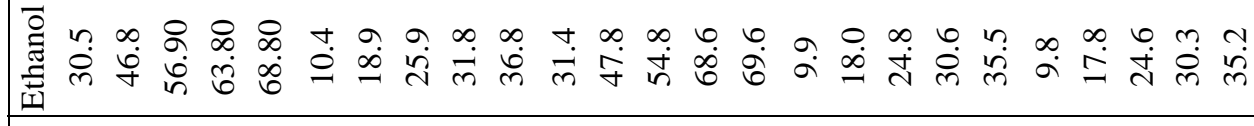 \\
\hline 崖 & 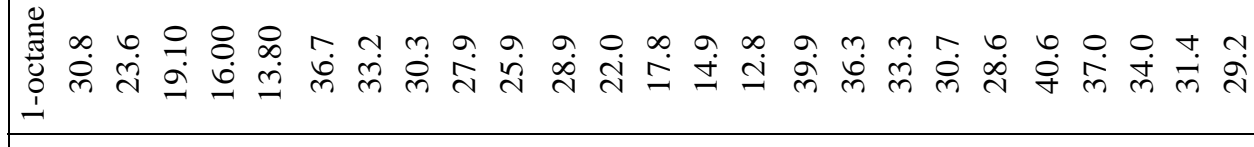 \\
\hline & 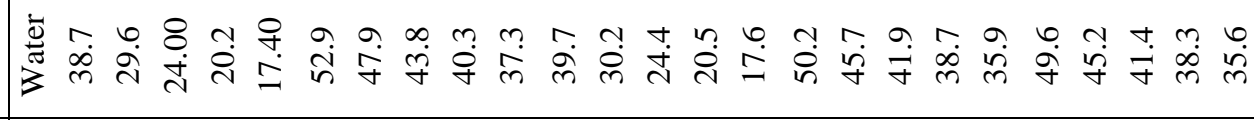 \\
\hline 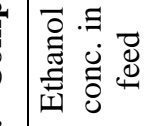 & 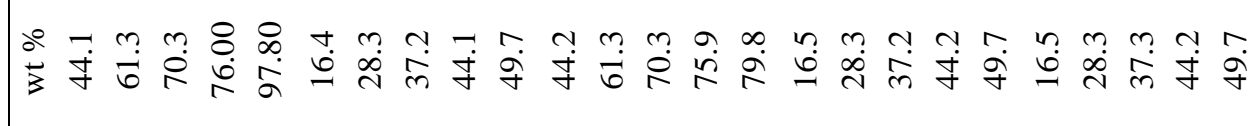 \\
\hline$\frac{\overrightarrow{0}}{2}$ & ì 荧 \\
\hline
\end{tabular}




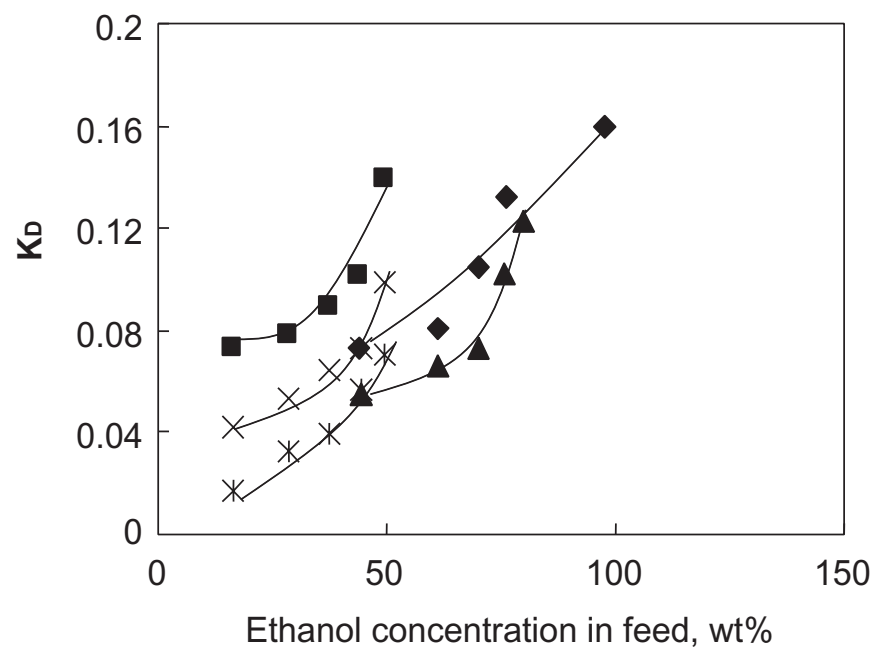

Fig. 3. Effect of ethanol concentration in feed on distribution co-efficient of ethanol. $(\diamond) 1$ - octane, ( ) iso-octane, $(\Delta)$ petrol, $(x)$ kerosene and $(*)$ diesel.

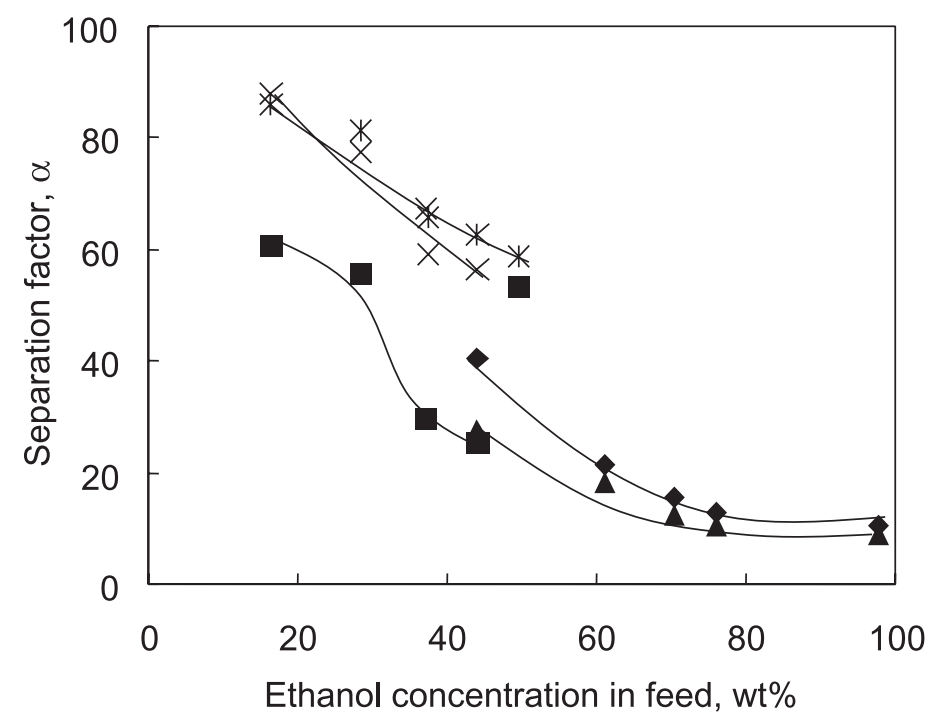

Fig. 4. Effect of ethanol concentration in feed on separation factor of ethanol. ( $\bullet) 1-$ octane, ( ) iso-octane, $(\Delta)$ petrol, $(\times)$ kerosene and $(*)$ diesel. 
the two - liquid - phase regions of ethanol water - iso-octane, ethanol - water - 'octane' and ethanol - water - 'petrol' are almost the same. The concentration of ethanol in isooctane-rich phase is higher than those in 'octane' and 'petrol'-rich phase respectively; and the negative gradients of the tie lines of Figures 1a and 1d are sharper than those of Figure 1b. This shows the polarity order is 1-octane $>$ iso-octane $>$ 'petrol' $>$ 'kerosene' $>$ 'diesel' in order of strength. Therefore, the increase in number of carbon atoms in the chain of solvents results in wider heterogeneous zones and in decreasing solubility of the ethanol in the organic phase. The solubility of ethanol in different higher hydrocarbons is found in the order of 'octane' $>$ isooctane > 'petrol' > 'kerosene' > 'diesel'.

It is seen from the Figure 3 that the distribution coefficient of ethanol (KD) increases with increasing concentration of ethanol in the feed solution and large values of distribution coefficient of ethanol are desirable since less solvent will then be required for the extraction. The order of the KD value for different hydrocarbon solvents is iso-octane $>$ 'octane' > 'petrol' > 'kerosene' > 'diesel'. This indicates that ethanol has preferential solubility in solvents as desired in the extraction process. The separation factor decreases with increasing concentration of ethanol in the feed solution as shown in Figure 4. The separation factors are considerably greater than 10 for all the solvents studied. The order of the separation factor is petrol < 'octane' < iso-octane < 'kerosene' . 'diesel'.

\section{Conclusions}

The binary systems of water - hydrocarbon solvents are partially or completely immiscible, and the binary systems of solvent ethanol are miscible at temperature, (25 \pm $0.1)^{\mathrm{O}}$ C. Therefore, these solvents may be used as effective solvents for the extraction of ethanol from aqueous solution with an opportunity of their subsequent separation from the product. The order of the heterogeneous region of the solvents in the binodal curve is 'octane' . iso-octane . 'petrol' < 'kerosene' < 'diesel'. The equilibrium time for ethanol - water - solvent systems is about $10 \mathrm{~min}$ and the settling time is about $20 \mathrm{~min}$. The solubility order of ethanol in the solvents is 'octane' > iso-octane > 'petrol' > 'kerosene' > 'diesel'. The distribution coefficient increases with increasing ethanol concentration in the feed; however, the separation factor is completely opposite. The distribution co-efficient is lower than 1 for all solvents and that of the separation factor is greater than 10 for all of the solvents. Therefore, it is concluded that gasoline commercially sold as 'octane', 'petrol' and 'diesel' in the local gas station can extract ethanol from its dilute aqueous solutions and this will enable one to produce 'gasohol' by a once through operation without involving separation of solvent. 


\section{References}

Bridgwater, A.V. (1996) An Introduction to Fast Pyrolysis of Biomass for Fuels and Chemicals, Fast pyrolysis of biomass: A hand book, edited by Bridgwater, A.V. Czernik, S. Diebold, J. Meier, D. Oasmaa, A. Peacocke, C. Piskorz, J. Radlein, D. (CPL Scientific Publishing Services Limited, Newbury) pp 1-19.

Choi, P.H. Jun, K.W. Lee, S.J. Choi, M.J. and Lee, K.W. (1996) Hydrogenation of carbon dioxide over alumina supported Fe-K catalysts. Catal. Lett. 40(1-2), 115-118.

Pimentel, D. (2003) Natural Resources Research. 2nd Ed. (Springer, Amsterdam), pp127.

Rahman, M.A. Rahman, M.S. and Asadullah, M. (1995) Production of fuel grade ethanol from aqueous solution by liquid-liquid extraction using vegetable oils as solvents. Indian J. Chem. Tech., 2, 90-92.
Tomishig, K. and Asadullah, M. (2005) In Progress in Catalysis Research. Edited by Bevy, L. P. (Nova Science Publishers, lnc., New York) pp 1.

Wang, C.Xu. and L. Wang, Q. (2003) Review of Directly Producing Light Olefins via CO hydrogenation. J. Nat. Gas Chem. 12 : 1015.

Zhang, Y. Jacobs, G. Sparks, D.E. Dry, M. E. and Davis, B.H. (2002) $\mathrm{CO}$ and $\mathrm{CO}_{2}$ hydrogenation study on supported cobalt FischerTropsch synthesis catalysts. Catal. Today $\mathbf{7 1}$ (3) : 411-415.

Received : December 03, 2006;

Accepted : August 22, 2007 